\title{
Vacinação precoce para doença respiratória em bezerras Holandesas
}

Viviani Gomes", Karina Medici Madureira, Marina Mozgovoj, Diego D Gonzalez, Camila Costa Baccili, Karen Nascimento da Silva, Jean Silva Ramos, Camila Cecília Martin, Natália Sobreira Basqueira, Edviges Maristela Pituco

Faculdade de Medicina Veterinária e Zootecnia, Universidade de São Paulo (USP), São Paulo, SP, Brasil

*Autor correspondente

e-mail: viviani.gomes@usp.br

\section{Resumo}

Esta pesquisa avaliou a eficácia da vacinação como estratégia para a prevenção de Doença Respiratória Bovina (DRB) em bezerras Holandesas na fase de aleitamento. Este estudo foi realizado na fazenda Colorado, em Araras/SP. Foram incluídas nesta pesquisa apenas bezerras saudáveis, distribuídas em 2 grupos: vacinadas (VAC, $n=18$ ) e não vacinadas (NVAC, $n=10$ ). 0 perfil sanitário das bezerras foi avaliado pelo escore de DRB padronizado pela Universidade de Wiscosin-Madison, associado ao leucograma. Além disso, o perfil de anticorpos neutralizantes para as viroses respiratórias foi determinado pela técnica de soroneutralização (SN). Escore respiratório foi realizado duas vezes por semana entre o D14 e D56, enquanto o leucograma e a SN foram avaliados em momentos pontuais: D14 (vacinação), D35 (booster) e D56 (21 dias após o booster). Detectou-se uma tendência ( $\mathrm{P}=0,072)$ para maior ocorrência de DRB no grupo NVAC (35\%) comparada ao VAC $(20,3 \%)$ após o booster, utilizando-se o qui-quadrado $\left(\mathrm{X}^{2}\right)$. A comparação entre grupos e tempos para o leucograma foi realizada pelo 2-way ANOVA. Observou-se tendência para maiores valores de leucócitos - Le (células x 10 $/ \mu \mathrm{L}$ ) no NVAC nos momentos D35 (VAC =6,1 $\pm 2,45$; NVAC = 7,86 $\pm 2,6, \mathrm{P}=0,076$ ) e D56 $(\mathrm{VAC}=6,70 \pm 2,02 ; \mathrm{NVAC}=8,68 \pm 2,55, \mathrm{P}=0,057)$. No tempo, Le diminuíram entre D14 (10,3 $\pm 3,19)$ e D56 $(8,68 \pm 2,55)$ no VAC $(\mathrm{P}=0,000)$, enquanto que NVAC manteve valores constantes entre D14 $(8,77 \pm 2,93)$ e $\mathrm{D} 56(6,7 \pm 2,02, \mathrm{P}=0,005)$. Neutrófilos - $\mathrm{Ne}$ (células $\times 10^{3} / \mu \mathrm{L}$ ) apresentaram tendência a menores valores no VAC em relação ao NVAC no D35 (VAC = 3,11 \pm 1,36; NVAC = 4,60 \pm 2,47, P = 0,062). Observou-se diminuição dos valores Ne entre D14 $(5,63 \pm 2,24)$ e D56 $(3,06 \pm 1,22)$ apenas no VAC $(\mathrm{P}=0,000)$. Os títulos de ACs apresentaram distribuição não normal, sendo analisados entre os grupos pelo Mann-Whitney e entre os tempos pelo Friedman e Wilcoxon. ACs neutralizantes $\left(\log _{2}\right)$ para BRSV foram constantes no VAC entre D14 $(2,98)$ e D56 (1,99) $(\mathrm{P}=0,150)$, porém NVAC apresentou queda no tempo (D14 = 2,98; D56 = 1,49, $\mathrm{P}=0,046)$. 
ACs para BPI3-V $\left(\log _{2}\right)$ aumentaram do D14 $(4,98)$ ao D35 $(6,97)$ no NVAC, observando-se diminuição em D56 $(5,48)(P=0,002)$. ACs para BPI3-V $\left(\log _{2}\right)$ também aumentaram no VAC do D14 $(5,91)$ para D35 $(6,97)$, com diminuição em D56 $(5,97)(P=0,000)$. Houve diferenças entre NVAC e VAC no D56 $(P=0,03)$. ACs para BVDV $\left(\log _{2}\right)$ foram constantes no NVAC entre D14 $(6,31)$ e D56 $(6,31)(P=0,417)$, entretanto os valores oscilaram no VAC observando-se aumento entre D14 $(7,30)$ e D35 $(8,3)$, e decréscimo no D56 $(7,3)(P=0,011)$. A dinâmica de ACs para o BoHV-1 foi semelhante entre grupos, observando-se diminuição entre $\mathrm{D} 14(\mathrm{NVAC}=8,96 ; \mathrm{VAC}=8,96)$ e $\mathrm{D} 56(\mathrm{NVAC}=6,97 ; \mathrm{VAC}=6,97)(\mathrm{P} \leq 0,05)$. A vacinação das bezerras aos 14 dias de idade garantiu alguma proteção nos primeiros meses de vida, comprovada por uma tendência à menor ocorrência de broncopneumonias associada à menor resposta leucocitária, além da manutenção ou maior produção de ACs para BRSV e BPI3-V após o booster. 